\title{
VIVENDO ENTRE EXPOSIÇÕES E AGRAVOS: A TEORIA DA RELATIVIDADE DO RISCO
}

\author{
LIVING AMONG EXPOSURES AND AILMENTS: \\ THE THEORY OF RISK RELATIVITY
}

Luis David Castiel*

\begin{abstract}
CASTIEL, L. D.: 'Living among exposures and ailments: the theory of risk relativity'. História, Ciências, Sauide - Manguinhos, III (2):237-264, Jul.-Oct. 1996.

The paper addresses conceptual and theoretical aspects of the construction of the category 'risk' within disciplines related to safety engineering, epidemiology, and actuary sciences. The role of molecular biology is highlighted in particular. Repercussions are examined not only in psychological and sociocultural terms but also from the perspective of social communication. Relations between the notions of risk, life style, and late modernity are also discussed. Lastly, the multiple dimensions of the idea of the 'relativity' of a risk are considered: this construct is produced with in a particular era; it is tied in with a certain view of the world and of human experience, thereby influencing theoretical and methodological approaches.
\end{abstract}

KEYWORDS: risk, epidemiology, late modernity, life style.

"A pesquisa científica cria sempre mais novas questões do que respostas a perguntas antigas."

Henri Atlan

*Professor do Departamento cle Epidemiologia e Métodos Quantitativos em Saúde, Escola Nacional de Saúde Pública/ Fundação Oswaldo Cruz. Rua Leopoldo Bulhões 1480 sala 829 Manguinhos Rio de Janeiro 21041-210 e-mail: Castiel@nutecnet.com.br

\section{Introdução}

Nos dias de hoje, a noção de risco desfruta de uma peculiar popularidade em diversos cantos do mundo. Se ser 'popular', em termos usuais, relaciona-se a uma idéia de difusão, reconhecimento e, digamos, aceitação pública, tal circunstância é flagrante. Para além dos contextos biomédicos/epidemiológicos, da saúde ocupacional e das ciências atuariais, fala-se e escreve-se com freqüência sobre risco nos chamados mass media. Percebe-se, também, que as pessoas, em suas esferas particulares, incorporaram, de alguma forma, a idéia de risco. Mesmo que as resultantes em termos comportamentais sejam distintas: ou acatála, procurando administrar os modos de viver - comer, beber, exercitar-se, expor-se ao sol, manter relações sexuais etc.; ou desafiando-a, adotando estilos de vida considerados arriscados, na suposição, possivelmente, de possuir imunidades imaginárias. 
1 Nestas circunstâncias, a idéia de predição não costuma ser determinista, como o termo poderia sugerir, mas, sim, probabilista. Como veremos, mesmo com o avanço da testagem genética, as predições (na acepção 'profética') da medicina só são válidas no atual estado da arte para algumas doenças específicas (como a Coréia de Huntington). Predições do risco (probabilidades) a partir dos conhecimentos disponíveis sobre as relações entre exposições/agravos na maioria das doenças, adquirem relevância aposteriori, após a ocorrência do agravo. Isto confirmaria as relações de causação, mesmo que se desconheçam os mecanismos precisos deste processo. Para alguns autores, no entanto, a ciência só se legitima, de fato, com a descoberta dos mecanismos (Atlan, 1994). Com o surgimento de estudos de medicina experimental e epidemiologia baseados na biologia molecular, a determinação dos riscos vai, em algumas circunstâncias, se tornar mais bem demarcada, permitindo predições com menores margens de erro.
Parece existir coletivamente uma percepção de pairar uma aura de ameaça sobre todos nós, podendo se efetivar, de modo particularizado, a qualquer instante. Especialmente, se não nos precavermos como mandam os preceitos da prevenção em saúde, das normas de segurança no trabalho, das precauções nas atividades cotidianas não só urbanas mas, também, rurais (vide o uso inadequado de agrotóxicos). Como diz Beck (1992), vive-se em uma sociedade globalizada de risco - uma sociedade catastrófica. Sua afirmação se dirige, por um lado, ao contexto capitalista avançado, onde se destacam os riscos de acidentes (hazards) tecnológicos de caráter coletivo, resultantes do processo de modernização destas formações sócio-econômicas. Por outro, assinala os riscos da pobreza nas sociedades da escassez no dito Terceiro Mundo e também nos bolsões de pobreza dos cantões afluentes do mundo industrializado.

Vale ressaltar a existência de uma verdadeira indústria de determinação/avaliação de riscos ligados à dimensão tecnológica (risk assessment), baseada em disciplinas ligadas à engenharia, toxicologia, epidemiologia/bioestatística e ciências atuariais, institucionalizada na Society for Risk Analysis e com a publicação Risk Analysis (Gabe, 1995). Certamente um dos principais elementos que participam na construção do "espírito de risco" de nossas sociedades modernas pode ser localizado no terreno da abundante produção científica. Há grande quantidade de investigações sobre tal temática acumulada nas últimas três décadas. Uma hipótese a considerar para tal quadro seria a ampliação do acesso à tecnologia computacional e a pacotes estatísticos. Uma conseqüência deste processo foi a "epidemia de risco", chamada assim por Skolbekken (1995), um psicólogo norueguês. Após realizar uma pesquisa bibliográfica acerca do uso do conceito, nas publicações da área da saúde, aponta a progressiva e acentuada elevação na "incidência" de artigos sobre o tema nas revistas médicas e epidemiológicas de países anglo-saxônicos e escandinavos no período 1967-91. Da mesma forma, Carter (1995) mostra como a palavra risk aparece em referências citadas na base de dados Excerpta Medica cerca de 5.500 vezes em 1980, chegando até valores próximos a 15 mil em 1993.

Segundo Hayes (1992), é possível agrupar as áreas desta produção científica (que, inevitavelmente, se embricam) em:

a) verificação/mensuração - como suporte a estratégias preventivas na interação na clínica médica. Aqui se incluem as práticas da chamada medicina prospectiva ou preditiva, cujas intervenções preventivas ocorrem a partir da identificação de exposições a fatores de risco; ${ }^{1}$

b) análise/avaliação/administração - dirigida a riscos ocupacionais, controle e segurança de produtos industrializados e percepção pública (ligada à Society for Risk Analysis); 
c) baseada no enfoque de risco epidemiológico - voltada para a chamada dimensão da saúde pública. Pode estar referenciada a dois domínios - ambiental: aborda riscos provocados por exposições a resíduos radiativos, poluentes tóxicos e outros subprodutos de atividades econômicas e sociais; e individual: lida com riscos resultantes de 'escolhas' comportamentais pessoais, colocadas sob a rubrica estilo de vida.

Como veremos adiante, a proliferação de estudos sobre risco teve repercussões em termos de difusão pública através dos meios de comunicação de massa. Por ora, cabe assinalar o estabelecimento de uma retroalimentação cibernética entre emissores e receptores das informações. Em função da divulgação de informações consideradas vitais para a sobrevida das populações, há o imediato interesse do público por tais questões (especialmente, diante da possível imputação de irresponsabilidade, caso se assumam posturas desacauteladas a este respeito), propiciando uma demanda para a qual os meios de comunicação de massa (MCM) procuram apresentar as "últimas descobertas da ciência" sobre os riscos, entre outros tópicos.

Um dos encaminhamentos possíveis para o público, diante das configurações de risco divulgadas, é buscar o setor econômico responsável pela oferta/comercialização de produtos de proteção/ prevenção aos riscos. Temos, então, serviços, práticas, bens de consumo de diversos tipos para enfrentar/prevenir as potenciais ameaças à nossa saúde. Sem, no entanto, é importante assinalar, haver garantias incondicionais que, procedendo-se assim, estaremos, incondicionalmente, protegidos. Pois, o risco é uma entidade probabilística. Em geral, as situações de exposição não se apresentam de modo a permitir que as previsões dos agravos sejam certas, imediatas, indiscutíveis. Sempre há a possibilidade de ocorrerem imponderabilidades incontroláveis.

Isto não é negligenciável. Assim, é possível perceber a emergência de discursos populares de resistência à ideologia do risco, ao recusarem as características inerentes aos pressupostos da probabilidade. São facilmente identificáveis e consistem em facetas da mesma moeda. São representados por dois modelos básicos, muitas vezes baseados em casos ocorridos na esfera pessoal: a) alguém de idade avançada, cuja exposição a fatores de risco no decorrer da vida não alterou sua saúde ou sobrevida; e b) alguém no "vigor da juventude", sem história de exposição, que, inesperadamente, sucumbe em virtude de um evento vinculado a reconhecidos fatores de risco (Davison et al., 1991).

Para prosseguir, uma breve descrição dos aspectos semânticos do termo. 
${ }^{2}$ Há distintas teorias de probabilidade, com cálculos e interpretações próprias. Além da ótica "freqüentista", temos a "probabiliclade bayesiana", "pessoal" ou "subjetiva", que procura considerar o fato de os humanos possuírem previamente crenças, opiniões, preferências, refletidas por seu comportamento real ou potencial, passiveis de influir na probabilidade de ocorrência de determinados eventos. Por outro lado, há literatura que procura demonstrar o fato de as pessoas não se comportarem de modo subjetivo bayesiano (Oakes, 1990; Poole, 1988).

\section{Sentidos de risco}

Risco é um vocábulo especialmente polissêmico e, portanto, dá margem a muitas ambigüidades. Como foi desenvolvido em artigo de minha autoria (Castiel, 1994), o referido termo possui conotações no chamado senso comum. Nessa perspectiva, há controvérsias quanto suas origens: tanto pode provir do baixolatim risicu, riscu, provavelmente do verbo resecare, cortar, como do espanhol risco, penhasco escarpado. Na segunda acepção, excluindo os termos relacionados ao verbo riscar, indica, por um lado, a própria idéia de perigo e, por outro, sua possibilidade de ocorrência (Ferreira, 1986).

No século passado, seu sentido estava relacionado a apostas e chances de ganhos e perdas em certas modalidades de jogos (ditos de azar). Em épocas mais recentes, adquiriu significados referidos a desenlaces negativos (Douglas, 1986). No decorrer da Segunda Guerra Mundial, no campo da engenharia, o tema recebeu um forte impulso em função da necessidade de estimar danos decorrentes do manuseio de materiais perigosos (radiativos, explosivos, combustíveis). Na biomedicina, estas análises serviram para dimensionar os possíveis riscos na utilização de tecnologias e procedimentos médicos (Skolbekken, 1995).

No Dicionário de Epidemiologia (Last, 1989), o verbete risco faz menção: à probabilidade de ocorrência de um evento (mórbido ou fatal); e como um termo não-técnico que inclui diversas medidas de probabilidade quanto a desfechos desfavoráveis. ${ }^{2}$ A própria idéia de probabilidade pode ser lida de dois modos: intuitivo, subjetivo, vago, ligado a algum "grau de crença", isto é, uma incerteza não-mensurável; e objetivo, racional, precisável mediante técnicas probabilísticas - incerteza mensurável (Gifford, 1986).

Nesta segunda acepção, está calcada a abordagem dos fatores de risco, isto é, marcadores que visam à predição de morbimortalidade futura. Desse modo, poder-se-ia identificar, contabilizar e comparar indivíduos, grupos familiares ou comunidades em relação a exposições a ditos fatores (já estabelecidos por estudos prévios) e proporcionar intervenções preventivas. Como diz Ayres (1995, p. 115):

"a particularidade que permite identificar a discursividade própria da epidemiologia, pode ser sinteticamente descrita pelo conjunto indissociável de três características que nos levarão à interrelação elucidadora entre a epidemiologia do risco e seus antecessores: uma pragmática do controle técnico; uma sintaxe do comportamento coletivo e uma semântica da variação quantitativa". 
3 No caso de uma amostra de cem inclivíduos, a unidade é obticla através da divisão por cem, mas o indivíduo 'produzido', nesse caso, é apenas um construto médio resultante da operação. Por exemplo, o resultado de uma pesquisa de usuários de televisão por assinatura para estabelecer o perfil de seu assinante afirma tratar-se de homem, de 45 anos, profissional de nivel superior, com renda familiar ao redor de quatro mil reais etc. Isto é, obviamente, uma construção abstrata a partir clas médias obtidas em cada aspecto mensurado.
$\mathrm{Na}$ epidemiologia, há três formulações básicas de risco: absoluto, relativo e atribuível. É importante, aqui, fazer dois comentários. Em primeiro lugar, é comum dizer-se que a taxa expressa o risco. Segundo Last (1989), isto é pertinente caso seja aplicado às situações apresentadas, no sentido mais restrito de taxa, ou seja, como quocientes que representem mudanças no decorrer do tempo. Além disso, o conceito taxa também é polissêmico, mesmo no interior da epidemiologia. Dessa forma, para ele, nas situações a seguir, taxa não expressa risco:

1) quando sinônimo de quociente, referindo-se a proporções. Por exemplo: taxa de prevalência; e

2) quando quociente que representa mudanças relativas (reais ou potenciais) em duas quantidades (numerador e denominador). Por exemplo: taxa de colesterol no sangue.

No entanto, estas distinções não são consensuais. Outros epidemiologistas diferenciam claramente "taxa de incidência" e "risco de adoecer", tanto em termos conceituais como nos métodos de estimação. A primeira estaria referida ao potencial instantâneo de mudança na situação de saúde (casos novos) por unidade de tempo, no tempo "t", relativo ao tamanho da população de interesse (sem agravos), no tempo "t" (a medida é expressa em unidades de 1/tempo ). O segundo se definiria como "a probabilidade de que um indivíduo sem doença desenvolva-a no decorrer de um período especificado de tempo, desde que o indivíduo não morra por outra causa durante tal período" (Kleinbaum et al., 1982, p. 99). Sendo probabilidade condicional, varia de zero a um e não possui unidades de medida.

As discordâncias permanecem nas tentativas de distinguir entre os enfoques individual/coletivo do risco e suas correspondentes estimativas. Desse modo, haveria métodos que encaram risco como medida (teórica) de probabilidade individual de ocorrência de agravo "A" — os atuariais; e aqueles que dimensionam a "força de morbidade" em populações - razões de densidade de incidência (Czeresnia e Albuquerque, 1995).

Em segundo lugar, como não é possível observar simultaneamente o efeito da exposição e não-exposição no mesmo indivíduo (idem, ibidem), o dispositivo estatístico-epidemiológico opera com grupos populacionais baseado no pressuposto de que a diversidade dos indivíduos distribuir-se-á de modo homogêneo nas amostras devidamente selecionadas. Os cálculos produzem taxas médias que refletem, portanto, valores referentes aos agregados (efeitos causais médios). Se, porventura, quisermos representar a unidade através do quociente relativo à quantidade observada pelo mesmo valor, é óbvio que esta não representa nenhum "indivíduo", que, assim, se torna uma abstração. ${ }^{3}$ Portanto, o risco é um achado relativo à dimensão agregada. Sua validade 
para o nível individual dá margem a erros lógicos. Estas questões são estudadas na epidemiologia (e na sociologia) sob a rubrica das falácias ecológicas, de dois tipos, conforme a operação: atomística ou agregativa (Susser, 1973): o que é válido para o nível agregado pode não o ser para o nível do indivíduo, ou vice-versa.

\section{Aspectos epistemológicos, teóricos e disciplinares}

Epidemiologistas, em geral, não costumam colocar em questão aspectos que problematizam a construção dos conhecimentos sobre o(s) risco(s), em especial sob o ponto de vista de suas pretensões preditivas (Almeida Filho, 1992). Nesse sentido, Hayes (1991) faz uma aguda análise de limitações implícitas nesta abordagem. Para ele, é essencial estar-se atento a determinados tópicos:

1) Regularidade dos efeitos empíricos: não podem haver alterações nas relações entre os marcadores de risco e os eventos de interesse. Como os mecanismos causadores dos agravos, na maioria das vezes, são desconhecidos, estes não devem variar de modo inesperado. Trata-se, em suma, da metáfora da caixa-preta. Aliás, a dita "epidemiologia dos fatores de risco" também é chamada de "epidemiologia da caixa-preta" (Pearce, 1990). Em outras palavras, é essencial a estabilidade das condições de "existência" do objeto para que o sujeito investigador o apreenda com fidedignidade: nem o objeto de estudo pode variar em suas características, atributos, propriedades, nem suas inter-relações com o meio circundante, em termos espaço-temporais.

2) Definição do estatuto dos fatores de risco específicos: é fundamental saber claramente se o fator é determinante ou predisponente em relação àqueles tão-somente contribuintes ou incidentalmente associados. $E$ isto não costuma ser facilmente discernível em muitas situações, especialmente naquelas que envolvem a participação de aspectos ditos psicogênicos, ou, então, na recente controvérsia causada por estudos onde não se observaram efeitos da hipercolesterolemia na eclosão de doenças cardiovasculares em mulheres (Lupton e Chapman, 1995).

3) Fatores de risco pertencentes a niveis de organização distintos - social $x$ natural: há dificuldades para estabelecer precisamente os mecanismos e mediaçôes entre variáveis consideradas sociais (p. ex., desemprego, analfabetismo, pobreza etc.) e aquelas ditas biológicas (idade, estado imunológico, características genéticas), apesar de, em certos casos, aparentemente não parecer haver dúvidas quanto às relações entre elas (p. ex., miséria e mortalidade por causas perinatais).

4) Período de tempo considerado válido para a predição: é problemático lidar com exposições ocorridas em épocas transcorridas há longo tempo (mais de 15, vinte anos por exemplo) e/ou em quantidades reduzidas, no decorrer de longos intervalos 
cronológicos, de modo que não se torna possível garantir a relação causal no caso de ocorrência do agravo. Isto é especialmente relevante em exposições ocupacionais, onde não chegam a gerarse danos imediatos, só ocorrendo, eventualmente, após muitos anos (Hayes, 1991).

Uma das importantes críticas feitas ao enfoque quantitativista do risco consiste no fato de instituir uma entidade, que possuiria uma 'existência' autônoma, objetivável, independente dos complexos contextos sócio-culturais nos quais as pessoas se encontram. Em outras palavras, o risco adquire um estatuto ontológico, que acompanha, de certa forma, aquele produzido pelo discurso biomédico para as doenças, mas, possuidor de características próprias, ou seja, atributos de virtualidade, 'fantasmáticos'. Pois, a existência dos riscos pode ser invisível, uma vez que, nem sempre, é perceptivel por seus sinais/sintomas - objetos dos tradicionais instrumentos da semiologia médica. Muitas vezes, são necessários sofisticados exames laboratoriais para 'localizar' este arisco ser, capaz de se desenvolver de modo silente e traiçoeiro e tornar-se presente de modo ameaçador. Se, por um lado, a retórica do risco pode servir de veículo para reforçar conteúdos morais e conservadores (Lupton, 1993), por outro, redimensiona o papel da configuração espaço-temporal na compreensão do adoecer: 1) a biomedicina incorpora como sua tarefa a localização e identificação nos sadios seus possiveis riscos (oriundos de modalidades de exposição ambiental e/ou de suscetibilidades biológicas, mediante técnicas diagnósticas cada vez mais refinadas; 2) surge uma infindável rede de riscos em que comportamentos, sinais, sintomas e doenças podem confluir para se tornar fatores de risco para outras afecções (p. ex., hipertensão arterial como risco para doenças cardíacas); e 3) o eixo temporal assume maior importância nos modelos explicativos dos processos de adoecer (Armstrong, 1995).

Vemos, então, surgir no discurso e na intervenção biomédica uma nova condição medicalizável: o estado de saúde sob risco (Kenen, 1996), que traz importantes implicações: a) como substrato gerador de preceitos comportamentais voltados para a promoção e prevenção à saúde, em última análise, base do projeto de estender a longevidade humana ao máximo possível; b) no estabelecimento de laços com a produção tecnológica biomédica; c) na ampliação das tarefas da clínica médica - em outros termos, o surgimento de uma vigilância médica, como sugere Armstrong (idem); d) na criação de demanda por novos produtos, serviços e especialistas voltados para a prevenção dos múltiplos riscos; e e) no reforço do poder e prestígio dos profissionais responsáveis por atividades dirigidas a novas técnicas/programas de controle ou à pesquisa de fatores de risco (Kenen, 1996). 
4 Ver, por exemplo, o revival de estudos ecológicos usando modelos matemáticos não-lineares em Koopman, 1994.
Outra crítica, de cunho metodológico, reside no fato de abordarem-se complexos fenômenos interativos (biológicos/ psicológicos/sociais), através de técnicas lineares para estimação do risco, insuficientes para abranger a alta complexidade do fenômeno humano. Um dos encaminhamentos decorrentes da aceitação desta constatação é o desenvolvimento de procedimentos não-lineares para a modelagem matemática de sistemas dinâmicos. ${ }^{4}$ Nesta ótica, é preciso ter em mente que, a rigor, tais modelos são estatísticos. Consistem, basicamente, em representações abstratas constituídas por elementos com significados $\mathrm{e}$ interdependências no interior de estados de flutuação, variabilidade. Sua função primordial é estabelecer ordenações para interpretar as relações entre objetos que foram matematizados (Lima, 1995, comunicação pessoal). Ainda não se conseguiu modelar satisfatoriamente o comportamento dos indivíduos, a relação entre a frequiência de uma ameaça à saúde e a respectiva percepção, a dinâmica das decisões institucionais (conforme as relações de poder envolvidas) e as intermediações que interferem nos processos de produção de conhecimento (Levins, 1994).

Paralelamente às avaliações/mensurações quantitativas de risco, há diversas linhas de pesquisa que analisam as repercussões psicológicas e sociais do discurso e da percepção do risco. Gabe (1995) realizou uma detalhada descrição deste panorama disciplinar, que servirá de eixo para nossa breve aproximação.

Sob o ponto de vista psicológico, há estudos de percepção leiga que se caracterizam por uma proposta metodológica quantitativa similar àquelas empregadas pelas disciplinas 'riscológicas'. Trabalhos do final dos anos $60 \mathrm{e}$ início dos 70 se basearam em modelos behavioristas para estudar (e medir) níveis aceitáveis de risco a partir dos comportamentos sociais existentes, que definiriam as escolhas das pessoas diante de benefícios e riscos 'involuntários' - provenientes de avanços tecnológicos e seus eventuais acidentes (bazards) —, em comparação com benefícios e riscos 'voluntários' (como fumar ou dirigir em alta velocidade).

No final dos anos 70, a hegemonia do behaviorismo foi abalada pelos marcos referenciais da psicologia cognitivista. Seus representantes desenvolveram múltiplos instrumentos de pesquisa, que incluíam escalas psicométricas e questionários para identificar os critérios pelos quais as pessoas avaliavam determinados perigos em comparação com o julgamento dos expertos. Estudos canadenses e suecos descreveram diferenças na avaliação leiga de possíveis danos oriundos de usinas nucleares, uso de pesticidas, conservantes alimentares, tabagismo - percepções de alto risco e baixo benefício, enquanto que diagnósticos por raios $\mathrm{X}$, medi- 
camentos, vacinas são encarados como de baixo risco e alto benefício (Gabe, 1995).

Outras correntes investigativas procuram destacar o papel do indivíduo como sede da conduta, ao invés de enfocar atributos específicos dos riscos. Assim, os comportamentos das pessoas são vistos em relação aos modos como sistemas de crenças e valores influenciam as respectivas percepções de risco. Um dos exemplos desta vertente é constituído pelo modelo das crenças em saúde (MCS). Sob esta ótica, há fatores preditores de comportamentos, que podem ser agrupados em quatro categorias: suscetibilidade percebida (percepções de ameaças à saúde); severidade percebida (avaliações pessoais da gravidade de tais ameaças); beneficios percebidos (avaliações pessoais quanto à factibilidade e efetividade das recomendações para lidar com a ameaça); barreiras percebidas (avaliações pessoais dos obstáculos relativos às ações de saúde). O MCS postula que os indivíduos adotarão medidas preventivas conforme as percepções de severidade e suscetibilidade se os benefícios do novo comportamento superarem as barreiras (Janz e Becker, 1984).

Para as ciências sociais ligadas à saúde, risco pode ser melhor entendido como um construto, instituído histórica e culturalmente. A antropóloga Mary Douglas $(1992,1986)$ é considerada uma das mais produtivas pensadoras sobre tal temática. Seus estudos procuram apontar razões pelas quais diferentes culturas selecionam e colocam sua atenção em riscos específicos e, então, proscrevem determinadas práticas como parte integrante de seus sistemas de valores e crenças. Nessa perspectiva, parece que os grupos humanos, em geral, desenvolvem estratégias de preservação de seus elementos identitários (contidos em seus modos de viver), e tendem a culpabilizar o "estranho/estrangeiro", como responsável extrínseco pelos "riscos"/"males" que afligem a "harmonia" de suas respectivas organizações societárias. Isto se evidencia nas doutrinas e nas ações de movimentos extremistas, passados ou atuais.

As análises sob a ótica da sociologia da saúde procuraram abordar o problema a partir de dois níveis:

1) Específico - referente à dimensão individualizada das pessoas em termos da interpretação dos significados do risco e dos modos como isto interfere nas práticas em seus cotidianos. Podem assumir a forma de estudos: a) sobre percepções e comportamentos de risco, por exemplo: pesquisa sobre a construção leiga do risco genético de distrofia muscular de Duchenne em mulheres com casos da doença na família. Os resultados indicaram que as cifras de risco genético apresentadas são retraduzidas em termos das experiências relevantes da existência das pessoas envolvidas, como o desejo de ter filhos, 
5 Em 1942, uma empresa eletroquímica norte-americana obteve permissão governamental para enterrar $21 \mathrm{mil}$ toneladas de dejetos industriais numa área chamada Love Canal, em Nova York. Duas décadas e meia depois, o depósito foi penetrado por águas pluviais, provocando a dispersão das substâncias químicas nele contidas. A partir do local, foi observado um líquido negro de aparência oleosa e odor aromático que invadiu residências construídas nas áreas circunvizinhas. Moradores atribuíram ao líquido a responsabilidade por doenças e óbitos ocorridos na ocasião (Fernicola, 1983). relação conjugal estável (Parsons e Atkinson, 1992); e b) das relações entre conhecimento leigo e experto, por exemplo: a investigação sobre grupos populacionais constroem uma epidemiologia leiga a respeito dos riscos de doença cardiovascular, mesclando informações originárias de achados médicoepidemiológicos com elaborações do dito senso comum, às vezes, incluindo elementos fatalistas de caráter divino (Davison et al., 1991).

2) Geral - relacionada ao papel das estruturas e instituições sociais na configuração do risco, em especial, o papel dos meios de comunicação de massa nesta divulgação. Estes trabalhos estão principalmente dirigidos à área do HIV/Aids. Há, também, nos países ditos centrais, a denominada epidemiologia popular. Consiste em movimentos liderados por ativistas sociais diante de ameaças ambientais e/ou ocupacionais por resíduos tóxicos oriundos de processos industriais mal controlados, diante da falta de resposta efetiva e ágil por parte das instâncias governamentais administrativas ou acadêmicas (Brown, 1995).

Vale a pena deter-se neste tópico. Ele pode ser ilustrado no episódio conhecido como Love Canal, quando toneladas de resíduos potencialmente tóxicos foram despejados próximos a uma grande comunidade. ${ }^{5}$ Quando se detectou a poluição, três posições foram identificadas:

a) epidemiologistas (representantes da Saúde Pública) que colocaram em ação os habituais protocolos da disciplina para identificar os possíveis danos diante das exposições: estimar casos esperados de agravos em uma população adequadamente comparável; contar casos ocorridos no local em questão; comparar estes dois procedimentos usando testes estatísticos para evitar situações determinadas pela casualidade; e controlar vieses e confundimento e a precisão das observações (validade, confiabilidade);

b) residentes, sem disponibilidade para uma eventual mudança do local, negaram a existência de perigos; e

c) residentes com crianças pequenas ficaram temerosos e tendiam a atribuir quaisquer intercorrências ocorridas à poluição (Vineis, 1995).

Ou seja, as percepções de risco são distintas conforme aspectos sócio-culturais que incluem idade, gênero, renda, grupo social, ocupação, interesses, valores, conseqüências pessoais etc. E isto não pode ser negligenciado pelas autoridades sanitárias em suas intervenções epidemiológicas em saúde ambiental, cujas ações, muitas vezes, tardam em ocorrer. Pois, em geral, a atenção dos epidemiologistas está dirigida mais à significância estatística, o que, eventualmente, pode comprometer a "significância em termos de saúde pública", indicada por taxas de morbidade importantes 
${ }^{6}$ O conceito de epigênese empregado se refere à distinção entre o que é definido a partir de informação exclusivamente contida no genoma e o que é determinado a partir de uma possivel interação genesambiente. nos locais poluídos, independentemente de serem "esperadas" ou não (Brown, 1995), ou pela impossibilidade de garantir a não ocorrência de eventos cuja latência é prolongada.

\section{A 'molecularização' dos riscos}

Com o avanço das técnicas da biologia molecular, em geral, e das manipulações genéticas, em particular, o campo dos conhecimentos em saúde tem passado por profundas transformações (Castiel, 1994a). Chega-se a postular, inclusive, a emergência de uma 'nova genética', definida como "um corpo de conhecimentos e procedimentos baseados na tecnologia do ADN recombinante que cria informação sobre os gens que os indivíduos e as famílias portam" (Richards, 1993, p. 567).

Expande-se, também, o conhecimento sobre as próprias doenças genéticas. É possivel, mediante o uso de marcadores específicos, a testagem preditiva para determinar os portadores de genes defeituosos, tanto dominantes como recessivos, responsáveis por tais doenças, e também por enfermidades crônico-degenerativas, como alguns tipos de câncer. Além disso, já se começa a cogitar na possibilidade de, mediante terapêuticas das células da linha germinal (germ-line therapy), aplicarem-se vacinações genéticas nas futuras crianças para evitar enfermidades crônicas não-transmissíveis, como câncer, doença coronariana e assim por diante (Tannsjö, 1993).

Dentro do quadro referido anteriormente, tem recebido destaque dos meios de comunicação de massa os avanços da genética molecular (mendeliana) na detecção de doenças, em especial moléstias cardiovasculares e neoplasias. Nesse sentido, em todas estas circunstâncias, destaca-se o conceito de risco. Assim, temos doenças cujas determinações, sejam genéticas, sejam epigenéticas ${ }^{6}$ são bem demarcadas. Nestes casos, o modelo de risco desenvolvido pela epidemiologia moderna alcançaria alto grau de eficácia: o fato de determinados indivíduos portarem determinados genes ou receberem-nos do pai ou da mãe delimita com precisão satisfatória a probabilidade de desenvolverem tal ou qual enfermidade. Isto é, há condições de fechamento do sistema em jogo que permite a aplicação bem-sucedida do referido modelo.

Em outros termos, como já foi mencionado, para haver "regularidade dos efeitos empíricos", é preciso que sejam satisfeitas duas condições: para os mecanismos funcionarem de modo estável, não devem ocorrer alterações qualitativas no objeto supostamente detentor de ação causal; para os resultados possuírem consistência, é preciso que haja regularidade na relação entre o objeto e as condições externas que, porventura, tenham o poder de interferir nos mecanismos de ação (Santos, 1989). 
Existem outras doenças cujas configurações genéticas em termos moleculares não admitem uma clara identificação - o caso das desordens poligênicas (resultantes de mutações em quaisquer genes diferentes), ou naquelas em que as interações sócioambientais tenham peso. Aqui, as relações de risco podem não ser percebidas com os mesmos graus satisfatórios de precisão. Ainda assim, tem havido grande produção de trabalhos que procuram estabelecer relações entre exposições-agravos, independentemente das contingências de fechamento (e previsibilidade) dos fenômenos.

Entretanto, é indiscutível a importância dos avanços das técnicas da biologia molecular na apreensão dos elementos genéticos, na etiopatogenia de muitas enfermidades e distúrbios. No caso do câncer de ovário ou de mama, estudos mostram que cerca de $80 \%$ das mulheres portadoras de genes específicos irão desenvolver a neoplasia. Porém, apenas 3 a 5\% dos casos de câncer de mama ou ovário são de portadoras dos genes supostamente responsáveis pela doença (Richards, 1993).

Externamente à produção científica das afirmações de risco baseadas na genética mendeliana humana, é importante, como foi mencionado, levar em conta as percepções sociais relativas à idéia de hereditariedade e como esta pode ser responsabilizada pela gênese e desencadeamento de um grande número de condições e agravos à saúde. A importância deste aspecto se deve ao fato de estar relacionada a padrões de conduta que conduzam a situações tanto de exposição como de proteção.

Como ilustração originária do senso comum, é relativamente freqüente escutar-se (ou, até, falar-se) das características físicas, conforme 'puxam' traços de progenitores ou outros parentes consangüíneos, em uma conotação hereditária procedente (dadas as evidências fenotípicas). Isto já não é tão evidenciável no caso das idiossincrasias psíquicas/comportamentais das pessoas. Apesar de serem, conforme as contingências, atribuídas, 'hereditariamente' a determinado 'ramo' da família ao qual se alega menor, digamos, 'qualidade genética'.

Encontra-se bastante difundida a idéia de 'propensão' (proneness), com, inclusive, aparentemente, maior aceitação pública que a noção de risco, produzida pelos discursos científicos (Davison et al., 1991). Trata-se de uma retórica acerca dos padrões de adoecimento e de longevidade considerados hereditários no interior das famílias. Assim, não é incomum encontrarem-se enunciações de supostas tendências dos indivíduos adoecerem (e, até, morrerem) de enfermidades que acometeram seus pais/ avós etc. Como se houvesse, nestes casos, uma potencial determinação de carăter fatalista, definida a partir de ramos anteriores das respectivas árvores genealógicas. 
Parece que, a partir da possibilidade do acesso ao genoma humano, propiciada pela genética molecular, o modelo do risco, aparentemente, poderia confluir e se sobrepor ao discurso da propensão hereditária. E, com isto, adquirir um estatuto mais vigoroso, e, portanto, mais efetivo para sua aceitação pelo público. É importante, assim, levar em conta o surgimento de um novo discurso higienista baseado nos avanços da genética molecular. As repercussões desta possível potenciação da retórica do risco não são negligenciáveis. Isto pode ser observado, por exemplo, nas conseqüências sociais de caráter preconceituoso decorrente da mera possibilidade maior (alto risco) de soropositividade ao vírus HIV em indivíduos com trejeitos considerados efeminados. No caso dos exames do genoma, aspectos discriminatórios podem se ampliar, diante da ratificação proveniente de 'evidências genômicas' da condição de 'portador' baseada em indicações de suscetibilidade genética a uma série de afecções.

Talvez com a 'molecularização' da epidemiologia (especialmente, em sua vertente genética), os estudos possam lidar melhor com as limitações do modelo da caixa-preta. Espera-se que, com o uso de marcadores biológicos na pesquisa epidemiológica, possam-se controlar fatores de instabilidade do dispositivo de investigação. Desse modo, seria possível: delimitar um gradiente de eventos entre exposição e doença; identificar exposições e doses relativas a quantidades menores de agentes supostamente causais; redução de erros de classificação das variáveis estudadas; indicação de possíveis mecanismos de relacionamento entre exposição e doença; avaliação mais precisa de variabilidade e modificação de efeito; e refinamento na determinação de risco individual e grupal (Schulte e Perera, 1993).

Então, diante das apregoadas perspectivas de entreabrir-se a caixa-preta, as incertezas das avaliações do risco serão diminuídas em função da ampliação de seu poder preditivo? Em algumas circunstâncias, a resposta é afirmativa (casos de detecção de desordens recessivas monogênicas em fetos ou screening de portadores de genes para doenças genéticas específicas). Mas, na maioria dos casos, parece que temos de levar em conta Davison et al. (1994, p. 344) ao afirmarem que "a identificação das bases genéticas para um risco elevado é simplesmente um caso especial dentro do campo da geral do screening para o risco, mas, isto pode não ser evidente para o público leigo, nem para muitos geneticistas". Especialmente, se considerarmos elementos de imprecisão provenientes das contingências de lidar-se com: distúrbios poligênicos, variável expressão do material genético, imprevisibilidade da relação genes-ambiente, imprecisões ainda presentes na testagem genética mediante marcadores de ADN (apesar da precisão das técnicas ser alta, volta-se à probabilidade 
7 A Seção 'Ciência' da Folha de S. Paulo de 7.1.1996, em matéria intitulada 'A pista errada do dinossauro', aborda aspectos de estudos do $A D N$, que, a despeito das impropriedades mostradas no filme de Steven Spielberg, Jurassic Park, serve para descobrir "as origens de outros animais notadamente as diversas espécies de seres humanos que habitaram e habitam a Terra, como o extinto Homo erectus e o atual Homo sapiens". Neste texto, assinala-se que as seqüências de ADN "constituem o genoma, o conjunto do material genético de um ser, ou a 'receita' para a sua produção" (Bonalume Neto). para enunciá-la), aspectos de validade e controle de qualidade em testagem populacional, variabilidade nas respostas de indivíduos suscetíveis diante da positividade do teste (idem, ibidem).

Vale ressaltar que os conhecimentos sobre o ADN têm gerado duas representações metaforizadas a respeito de seu papel. Uma delas, ainda predominante, é a idéia de se tratar de um 'programa' determinista clássico, como o de computadores, cujo conteúdo define um desenrolar especificado de eventos, estipulado como uma receita seqüencial de estrutura binária. ${ }^{7}$ No entanto, como aponta Atlan (1994), nem todas as seqüências binárias são programas de computador. Caso não sejam aleatórias, é mais realista introduzir outra leitura complementar: a de se constituir em 'dados' existentes, disponíveis a serem utilizados, mas, sem a noção de determinismo fechado, veiculada pela "metáfora programática". Tais dados são vistos como elementos tratados dentro de um processo dinâmico comparável ao das máquinas de inteligência artificial, capazes de adaptação, aprendizagem não programada e, em geral, de auto-organização estrutural e funcional.

Independente disto, o efeito social das definições de risco (mesmo genético) ainda não tem dependido de sua validade científica ou das metáforas instituintes da representação do ADN. Alguns estudos mostram resultados reveladores neste sentido. Por exemplo, a pesquisa, citada anteriormente, no País de Gales, acerca da percepção leiga do risco genético para mulheres, na eventualidade de se tornarem mães de crianças do sexo feminino - veiculadoras do gene defeituoso; ou do sexo masculino afetadas, por doença degenerativa ligada ao cromossoma $\mathrm{X}$, distrofia muscular de Duchenne. É possível, mediante história familiar, teste de creatinoquinase e estudos de ADN, chegar a estimativas (percentuais) de risco genético bastante acuradas.

Os resultados mostraram que, apesar do "nível cultural" da população inglesa, há tendências de os pacientes simplificarem os valores que lhes são transmitidos por geneticistas. Por exemplo, as estimativas transmitidas pelos geneticistas tornam-se " $50 \%$ / 50\%" ou risco "alto"/"baixo". Houve evidências de que grande quantidade de informação se perdeu no processo de tradução. $\mathrm{Na}$ realidade, os riscos genéticos e suas potenciais ameaças à saúde destas mulheres foram expressos em termos de riscos reprodutivos. Para elas, o que realmente importava era a capacidade de gerar bebês sadios (Parsons e Atkinson, 1992).

Outro estudo mostra como o conhecimento 'científico' do risco e da doença não era suficiente para encorajar o screening em funcionários de um departamento de genética molecular em um hospital londrino. Somente $20 \%$ do staff foram voluntários para a testagem oferecida para a condição de portadores de genes para fibrose cística (Richards, 1993). 
Em outras palavras, para decisões a respeito de tópicos de tanta importância, as informações devem ser transformadas em medidas existencialmente significativas. Ou seja, com todo o presumível rigor e potência do modelo de risco (mesmo genético), é preciso que ele tenha significação e importância para a vida das pessoas. De outra forma, tende a ser ineficaz para as finalidades sociais a que se destina. É evidente a ocorrência de descompassos entre as prescrições 'técnicas' baseadas no discurso 'riscológico' e suas correspondentes traduções no universo das representações (e valores) das pessoas.

Mas, diante da magnitude do discurso do risco, acoplado aos avanços da genética molecular, é essencial abordar aspectos da testagem preditiva, tais como:

- decidir a respeito dos testes que devem ser permitidos, oferecidos, estimulados ou requeridos;

- estudar a interface expertos (geneticistas) e comunicação social de achados científicos;

- investigar as repercussões psicológicas tanto individuais como sociais envolvidas com a testagem, em especial, considerar os resultados falsos e seus efeitos. Em especial, os efeitos do conhecimento dos respectivos riscos genéticos na evolução de agravos à saúde dos indivíduos portadores (os "riscos dos riscos"); e

- pesquisar os efeitos empregatícios, securitários e nas relações interpessoais (Davison et al., 1994).

Em suma, como sugere Atlan (1994), julgamentos devem ser feitos caso a caso, conforme circunstâncias e interesses envolvidos, incluindo aspectos como: tipo da doença, sua evolução, gravidade, incidência, caráter genético recessivo/dominante, entre outros.

\section{Risco e comunicação de massa}

Como já foi sugerido, os meios de comunicação de massa (MCM) encontraram nesta área um excelente filão. Vale salientar, aqui, o atual alcance do chamado jornalismo, científico, suas estratégias persuasivas e seus apelos populares. Um dos recentes exemplos, relevante ao nosso tema, pode ser visto na recente reportagem de capa da revista Veja, um conhecido semanário brasileiro de informação, de grande circulação, que estampa como chamada: "A saúde como herança. A genética descobre como prevenir doenças através do estudo dos problemas médicos de parentes".

Nesta reportagem, intitulada 'As pistas no álbum de família', mostram-se situações de risco onde se aventa a indicação de procedimentos preventivos, eventualmente radicais, diante de histórias familiares de, por um lado, vários tipos de câncer, diabete, doença coronariana, glaucoma e, por outro, doenças genéticas 'puras': fibrose cística, hipercolesterolemia familiar, hemofilia, dis- 
trofia muscular de Duchenne (Alcântara, 1995). Nesse caso, a matéria se apresentava, em geral, correta em termos cle orientação à saúde. Chegava, mesmo, a indicar que a "árvore genealógica ... revela probabilidades, mas não produz diagnósticos" (Alcântara, 1995, p. 90).

Mas não consegue evitar (será possível?) o uso metafórico ao mencionar que "a presença de um gene ruim na família significa apenas que há uma chance de alguém o ter herdado" (Alcântara, idem, ibidem). Em outras palavras, o gene se "torna" uma entidade antropomórfica. Temos, assim, genes "egoístas", "homossexuais", "hedonistas", "criminosos", "da genialidade", "da depressão", "da poupança", "do pecado", "da adição" (Nelkin, 1994).

Há indícios quanto ao aspecto mais atraente da informação, para a imprensa, ser a promessa de previsibilidade carreada por uma representação positivista da ciência. No caso das predisposições genéticas (que envolvem "genes ruins"), temos idéias implícitas de medição, classificação e controle e, conseqüentemente, possibilidade de ações preventivas contra os "males", inclusive aqueles que surgem sob a forma de comportamentos desviantes. Evitam-se, assim, imprecisões e ambigüidades das explicações de cunho social e/ou ambiental.

Ao mesmo tempo, os MCM acabam por exercer uma pedagogia, ao repetir narrativas e imagens que instituem juízos e modos de reagir diante de dilemas morais gerados pela sociedade contemporânea (idem, ibidem). Os jornalistas, quer queiram ou não, desempenham o papel de educadores (Atlan, 1994). Além disso, podem funcionar como fator de influência para a eventual adoção de medidas 'profiláticas'. Se as determinações genômicas são inevitáveis, a sociedade pode não se sentir responsável pela assistência aos afetados pelas "malformações" e adotar medidas eugenistas que refletem posições preconceituosas - o agora chamado "especismo" (para além do racismo e do sexismo).

A partir deste ponto de vista, é possível vislumbrar medidas, como o aborto, que, a partir de diagnósticos intra-uterinos de "genes ruins" no ADN, poderiam ser dirigidas para a "prevenção do homossexualismo". Haja visto as repercussões provocadas pela descoberta de um "gene gay", tal como foi traduzida pela grande imprensa escrita e televisionada da Grã-Bretanha a possível ligação entre genética e homoerotismo masculino divulgada pela revista Science (Miller, 1995).

É indiscutível o alcance e a difusão do chamado jornalismo científico nos MCM. Portanto, é preciso estar atento à relação entre cientistas da saúde e a difusão leiga de seus achados. Pois, não é inadmissível a geração de discrepâncias ou conflitos com prejuízo para os próprios investigadores e profissionais de saúde, mas, especialmente, para o público. Veja-se, por exemplo, as 
'epidemias' de determinadas afecções nos serviços médicos no dia seguinte à difusão das mesmas em programas televisivos.

Tais questões vêm se tornando prementes, a ponto de surgir uma publicação científica dedicada especificamente a esta problemática: Public Understanding of Science. Nesta ótica, é relevante, por exemplo, estudar o papel da retórica nos processos de comunicação dita científica (Gross, 1994), identificando, por exemplo, metáforas promocionais e seus efeitos (Nelkin, 1994).

Independentemente das motivações, não se pode negar $\mathrm{o}$ interesse das populações em temas relativos à saúde. Basta ver o espaço ocupado pelo jornalismo ligado às questões de saúde e medicina. A divulgação pública de resultados de investigações epidemiológicas vem, no entanto, sendo foco de celeumas e mútuas imputações de responsabilidade entre a respectiva comunidade acadêmica e os mass media. Epidemiologistas argumentam que jornalistas enfatizam em excesso achados de estudos específicos, sem dimensionar aspectos metodológicos e o contexto da pesquisa. Os representantes da imprensa se justificam comentando o afã de espetacularização de alguns pesquisadores e correspondentes instituições.

Esta polêmica foi apresentada em outra recente edição da Science. Na reportagem, destacaram-se as discussões entre epidemiologistas a respeito das limitações de suas abordagens diante da profusão de estudos inconclusivos para o estabelecimento de fatores de risco de diversas doenças a determinadas exposições. Com isto, os comitês editoriais de publicações médicas (como o Lancet e o New England Journal of Medicine) discutem a criação de critérios que envolvam, além dos aspectos de rigor metodológico, também os resultados obtidos - a magnitude do risco relativo encontrado (acima de três ou quatro) - para justificar a publicação do trabalho. Argumenta-se que os problemas de controle de erros sistemáticos (vieses) e confounding são, muitas vezes, incontornáveis. E, mesmo quando não parecem haver falhas a este respeito, os achados devem ser muito significativos para serem divulgados (Taubes, 1995).

De qualquer forma, a divulgação de questões de risco envolve relevantes aspectos bioéticos e aponta para a necessidade de uma base normativa para tal comunicação. A tal ponto que já existem tentativas de se estabelecer protocolos éticos para a comunicação de riscos tanto para a ciência como para os mass media (Valenti e Wilkins, 1995).

Nossa ênfase, aqui, é assinalar a importância de estudar como jornalistas científicos e profissionais de saúde (com ênfase na idéia de risco, genético ou não) constroem categorias e veiculam informações em suas áreas de especialização, de modo a, eventualmente, colaborar, de forma involuntária, com desinformações, 
8 Ver a este respeito Featherstone (1995). Este autor faz um admirável esforço de demarcar as sutis questões envolvidas nos pares modernidade/pós-modernidade; modernização/pós-modernização; modernismo/pós-modernismo. Para ele, "modernidade" carreia o sentido de "progressiva racionalização e diferenciação econômica e administrativa do mundo social ... - processos que resultaram na formação do moderno Estado capitalista-industrial" (p. 20). "Modernização" é, de certa forma, similar. Aponta para "os efeitos do desenvolvimento econômico sobre estruturas sociais e valores tradicionais", designa, ainda, "as etapas de desenvolvimento social baseadas na industrialização, a expảnsão da ciência e da tecnologia, o Estado-nação moderno, o mercado capitalista, a urbanização..." (p. 22). "Pós-modernidacle" é um termo ambi- estímulo a posições preconceituosas e, conforme o caso, a possibilidade de provocar desproporcionais reações alarmistas. Nesse sentido, é essencial considerar o contexto sócio-cultural onde acontecem as relações entre a produção de conhecimentos genéticos, as formas e processos de veiculação e a correspondente apropriação por distintos grupos humanos (MacIntyre, 1995).

\section{Tardo-modernidade, estilo de vida e risco}

Conceitos como modernidade e pós-modernidade (entre outras variantes) são objeto de múltiplos debates. Não é nosso propósito embrenhar um campo por demais complexo e controverso. Por exemplo, há autores que criticam a própria idéia de modernidade (Latour, 1994). Outros preferem a expressão "supermodernidade" (Augé, 1994), "modernidade tardia", "alta-modernidade", ou "tardomodernidade" (Giddens, 1991a) para identificar nossos tempos. Porém, não há consenso entre os autores sobre as correspondentes interpretações. Para os propósitos deste trabalho, que visa discutir o risco como um reflexo desta fase 'tardia' da 'modernidade', pós-tradicional, onde as correspondentes conseqüências estão se tornando radicalizadas e globalizadas, ${ }^{8}$ adotaremos, preferencialmente, a expressão de Giddens (1991b), em função, ao nosso ver, da pertinência de sua posição. É preciso ressaltar, contudo, a arrogância implícita na atual geração que julga viver numa era 'moderna' - 'estágio' culminante de um processo de evolução política, econômica e social.

O risco, visto em termos ambientais ou particularizado na idéia de estilo de vida, é um elemento estreitamente vinculado às sociedades tardo-modernas. Isto pode ser percebido nos modos como a construção da idéia de corpo e auto-identidade se dão no interior de uma cultura de risco (idem, ibidem). A idéia de controle e previsibilidade serve como elemento central para a gestão e domínio da natureza. Portanto, "risco ... se torna um parâmetro existencial fundamental da vida na tardo-modernidade tardia, estruturando o modo pelo qual experts e leigos organizam seus mundos sociais" (Williams e Calnan, 1996, p. 1.615). A noção se torna crucial "em uma sociedade que se descola do passado, dos modos tradicionais de fazer as coisas e que está se abrindo para um futuro problemático" (Giddens, 1991b, p. 111).

Em outras palavras, os modos de viver veiculados pela tardomodernidade provocaram descontinuidades abruptas na ordem social, seja como resultante das formas de vinculação societária globalizada, seja como produtora de transformações identitárias que se manifestam em nossas mais íntimas experiências pessoais.

Segundo Giddens (1991, p. 45), uma das características primordiais da vida nas sociedades tardo-modernas é a reflexividade, 
guo que indica, grosso modo, "um movimento em clireção a uma era pós-industrial", onde "novas formas de tecnologia e informação tornam-se fundamentais para a passagem de uma ordem social produtiva para uma reprodutiva, na qual as simulações $e$ modelos cada vez mais constituem o mundo, de modo a apagar a distinção entre realidade $\mathrm{e}$ aparência" (p. 20). Mas também pode dar uma icléia de uma "disposição de espírito", "estado da mente", onde se experimenta a vida contemporânea com "um sentido da descontinuidade do tempo, de rompimento com a tradição, de sentimento de novidade e sensibilidade com a natureza contingente, efêmera e fugàz do presente" (p. 21). isto é, a circunstância de que "as práticas sociais são constantemente examinadas e reformadas à luz de informação renovada sobre estas próprias práticas, alterando assim constitutivamente seu caráter". Se pensarmos sob a ótica da teoria dos sistemas complexos, os produtos dos processos retroagem sobre os próprios processos, modificando suas características/propriedades/atributos - a chamada sensibilidade às condições iniciais. Um exemplo relativamente corriqueiro: os efeitos da divulgação das pesquisas pré-eleitorais nos próprios resultados eleitorais.

Uma teorização pertinente sobre os produtos desta reflexividade foi desenvolvida por Latour (1994). Para ele, há uma proliferação de objetos híbridos, isto é, objetos mistos de natureza e cultura, dispostos em redes em que se atravessam vetores naturais, sociais e discursivos. Daí a dificuldade de apreendê-los através das disciplinas instituídas e institucionalizadas. Por exemplo, a Aids envolve vírus e linfócitos, identidades sexuais e respectivas representações discursivas, políticas de prevenção e de tratamento (discutidas em instâncias governamentais e não-governamentais), divulgação em meios de comunicação de massa e suas repercussões.

É importante frisar que tais configurações complexas não são exclusividade da era tardo-moderna, mas adquiriram, neste período, amplitude e profundidade tais que provocaram grandes transformações sócio-culturais e psicológicas. Uma delas foi o fato de a razão e a ciência serem subvertidas: o conhecimento deixou de possuir a vinculação que tinha com os ideais deterministas, como ocorria nos tempos pioneiros da razão científica. Conhecer, agora, não implica mais atingir certezas, incondicionalmente estáveis, plenamente garantidas em seu estatuto.

O conceito risco se inclui nesta perspectiva. Não se constitui em afirmações determinísticas, mas de possibilidade. Este tipo de conhecimento probabilístico, se, por um lado, permite a identificação de potenciais fontes de agravos e a adoção de medidas preventivas e de segurança, por outro, gera uma atmosfera de incerteza e ansiedade, diante da multiplicidade de fatores de risco e da ampliação da ambigüidade em se distinguir saúde/doença. Desafortunadamente, nem sempre os fatores de risco são 'verdadeiros', indiscutíveis. Conforme a situação, podem ser 'falsos', em virtude da divulgação precipitada de evidências insuficientes para estabelecer nexos causais, por aspectos metodológicos dos dispositivos de pesquisa: impossível garantir, sem dúvidas, o controle de vieses e confounding.

O risco, como já foi apontado, constitui as bases preditivas e legitimadoras para medidas de prevenção em saúde. O caso da Aids serve para ilustrar tais aspectos. Sua prevenção pode assumir dois modelos básicos: a) indivíduos portadores como potenciais 
fontes de contágio. Portanto, devem ser vigiados epidemiologicamente, e, eventualmente, apesar de não aparecer explicitamente, terem restringidos seus acessos a emprego, moradia, circulação; e b) busca de mudanças de comportamento através de difusão de informação, educação e aconselhamento (Scott e Freeman, 1995).

As tentativas de intervenção na Aids, servem para enfeixar dilemas e tensões da tardo-modernidade, entre eles: direitos do indivíduo e do Estado; autonomia individual e ordem social; estados e mercados; o nacional, o global e o local; o público e o privado (idem, ibidem).

Além disso, seguindo Carter (1995), o processo de avaliação de risco para a Aids exacerbou algumas dicotomias discursivas que servem como indicadores de fronteiras e estabelecimento de limites/territorialidade como tentativa de se proteger das ameaças: eu/outro; nós/eles; hetero/homossexual; maioria/minoria, ativo/ passivo; inocente/culpado; familiar/estranho; virtude/vício; correto/errado; normal/anormal; vida/morte; amor/sexualidade; científico/não-científico; conhecimento/ignorância; responsabilidade/irresponsabilidade.

Outro aspecto digno de ênfase diz respeito à diminuição da crença na autoridade dos sistemas 'expertos'. Apesar de todos os esforços de controle regulador racional, o conhecimento veiculado pelos especialistas não tem se mostrado relevante para as pessoas lidarem com as questões do mundo, da vida. Se, por um lado, as ciências proporcionaram explicações e tecnologias que eram desconhecidas da humanidade há pouco tempo, por outro, aspectos cruciais da condição/experiência humana permanecem como problemas. E, de certo modo, adquiriram novas facetas nos tempos atuais, nos quais as matrizes propiciadoras de estabilidade identitária e apaziguamento se enfraqueceram. A incerteza a nosso respeito, ao que nos cerca e nos aguarda compromete o valor atribuído ao conhecimento científico e a seus representantes (Uexkull, 1995).

O gerenciamento dos riscos (quando estes não são encarados em seu aspecto ambiental) é, muitas vezes, apresentado pelos expertos como algo ligado à esfera privada, da responsabilidade dos indivíduos, colocada em termos de escolhas comportamentais, enfeixadas sob a rubrica estilo de vida. As propostas educacionais visam atingir mudanças nesta dimensão.

A partir de tal ótica, interessam, no interior do dito estilo de vida de cada um, aquelas 'escolhas' e comportamentos com repercussões nos respectivos padrões de adoecimento das pessoas. Ou seja, no campo da cultura de consumo contemporânea, os aspectos perniciosos decorrentes de elementos que conotam "individualidade, auto-expressão e uma consciência de si estilizada. O corpo, as roupas, os entretenimentos de lazer, as preferências 
de comida e bebida, a casa, o carro, a opção de férias etc." (Featherstone, 1995, p. 119).

Levando tal raciocínio adiante, vamos nos deparar com uma idéia paradoxal. Se são atribuídas às pessoas suas escolhas de estilo de vida (dentro, é claro, de suas margens de aquisição/ acesso), incluído no 'pacote', estão embutidos fatores/elementos considerados responsáveis por possibilidades de ocorrências danosas à saúde. Então, não é absurdo supor este subconjunto como o 'estilo de risco', como se, de alguma forma, as pessoas também 'escolhessem' exposições a riscos como formas de levar suas vidas.

No entanto, tais opções não devem ser vistas como fruto de disposições intencionais, racionais, voluntárias. Cada um de nós é a resultante singularizada de complexas configurações bioquímicas, psicológicas, sócio-culturais, onde o estabelecimento e as tentativas de reordenação da idéia de si-mesmo são frágeis e dependem de contribuições genéticas, construções epigenéticas, biografia pessoal, estrutura psicológica inconsciente, elementos culturais, acasos. Portanto, os estilos de risco são, a rigor, aspectos que, muitas vezes, participam e constituem os modos possíveis com que se lida com o mundo, a vida tal como se faz presente a cada um de nós. Claro que determinados 'estilos' são perigosos, seja para o próprio indivíduo, seja, também, para os que o cercam. Assim, demandam intervenções apropriadas. Mas, é essencial não perder de vista a perspectiva descrita, sob o risco (!) de serem adotadas premissas que conduzam a ações insensíveis, culpabilizantes, limitadas e, conforme o caso, de efetividade restrita.

Um breve comentário sobre as origens e uso atual da categoria estilo de vida. Está registrada nas teorias sociológicas clássicas como componente da estratificação social, e, dentre elas, se destaca a visão de Max Weber ao enfatizar a importância do conceito na evolução e manutenção de status dos grupos (Backett e Davison, 1995). Recentemente, a noção tem sido debatida e polemizada por vários autores. Giddens (1991b), por exemplo, considera-o como um dos aspectos fundamentais da cultura da tardo-modernidade. Proporciona elementos para um senso de unidade e segurança existencial em um mundo incerto e ameaçador. Mas admite que depende das possibilidades de acesso e de aquisição.

Featherstone (1995), por sua vez, considera que a noção está na moda e pretende desenvolver uma abordagem que vá além da perspectiva de estilo de vida equivaler basicamente a padrão de consumo, manipulado pela chamada cultura de massa. Ou, então, que consista em uma categoria bem demarcada, com um domínio autônomo, além dos efeitos manipulativos. Nesse caso, 
o conceito de habitus de Bourdieu (1989) permitiria melhor entendimento. Descreve as disposições determinantes dos gostos que definem cada grupo social, incluindo elementos inconscientes, padrões classificatórios, predileções (explícitas ou não) relativas à idéia que o indivíduo faz de seus gostos e escolhas estéticas arte, comida, bebida, indumentária, entretenimento etc. - e de sua validade e valorização social. Mais ainda: está 'encarnado' na própria apresentação corporal de si-mesmo — forma e relação com o próprio corpo, fisionomia, postura, linguajar, padrões discursivos, modos de gesticular, andar, sentar, comer, beber etc. Cada grupo, classe e fração possui um habitus/estilo de vida próprio (Featherstone, 1995).

Uma crítica comum ao conceito estilo de vida é referente a seu emprego em contextos de miséria e aplicado a grupos sociais onde as margens de escolha praticamente inexistem. Muitas pessoas não elegem estilos para levar suas vidas. Não há opções disponíveis. Na verdade, nestas circunstâncias, o que há são estratégias de sobrevivência.

No campo da saúde, a categoria é muito usada nos terrenos da promoção, prevenção e da pesquisa comportamental em saúde. Apesar da grande produção teórica e empírica nos anos 80, o conceito ainda carece de clareza e precisão (Backett e Davison, 1995). A referência a comportamentos que representam fatores de risco no nível individual e medidas de promoção e prevenção em termos populacionais é insuficiente para representar satisfatoriamente as determinações e intermediações envolvidas. Quem são aqueles que assim agem? Quais são suas motivações e as relações aos contextos sócio-culturais? E, mais importante ainda, por que estas assumem determinadas modalizações? Quando muito, conhece-se o como...

Sabe-se que a pesquisa epidemiológica dos hábitos comportamentais costuma estudar determinadas condutas que aparecem estatisticamente associadas a configurações de morbimortalidade. Alguns trabalhos recentes criticam as limitações encontradas nos modelos usuais de pesquisa nesta área. Entretanto, apontam que, para abordar aspectos comportamentais, seriam necessários conceitos e técnicas estatísticas que levassem em conta que a "pesquisa do estilo de vida precisa enfocar a complexidade inerente aos modos de viver". Assim, "novos enfoques ... podem integrar conhecimentos e habilidades epidemiológicas e das ciências sociais com o fim de estudar padrões de comportamento nos contextos nos quais ocorrem ... para o propósito de estudar interações entre influências sociais e comportamentais" (Dean et al., 1995, p. 846). Para estes autores, os métodos analíticos seriam constituídos pelos modelos de interação gráfica, subtipo dos modelos log-lineares. 
A despeito da pertinência da crítica e das preocupações conceituais destes autores, suas proposições metodológicas ainda denotam a 'concretude' mensurável da categoria comportamento e, por extensão, dos estilos de vida, que poderiam ser 'melhor' apreendidos através do refinamento e adequação das técnicas de pesquisa. Isto se evidencia na afirmação de que "[comportamentos] interagem com influências biológicas, psicológicas e sociais para modelar tanto saúde como longevidade" (idem, ibidem). Não seria o caso de se pensar que comportamentos são, na verdade, resultantes dinâmicas e complexas de tais influências? Em outras palavras, de modo similar ao que ocorre com risco, há, aqui também, a reificação da categoria estilo de vida. Este fato evidencia a necessidade de os aparatos mensurativos pressuporem a 'existência' concretizada de seus objetos, para viabilizar as respectivas abordagens.

\section{Afinal, viver e a relatividade do risco}

Pode-se propor uma comparação: as epidemias de peste ou outras moléstias contagiosas e respectivas construções psicológicas/ sociais (CP/S), tal como se manifestavam antigamente, teriam sido substituídas predominantemente não só por enfermidades crônico-degenerativas, doenças infecciosas ditas emergentes (ou reemergentes) e eventos ligados à violência contemporânea (e suas $\mathrm{CP} / \mathrm{S}$ ), mas, também, pela 'pandemia' das idéias obsessivas referentes aos riscos da ocorrência destes agravos. Será que este quadro reflete, de fato, a ampliação do conhecimento sobre os perigos da vida contemporânea (que teriam, por sua vez, se ampliado, também)? Ou constitui-se em um artefato simbólico produzido pela construção social da tardo-modernidade: uma cultura de(o) risco. Ou, ainda, ambos, simultaneamente? Ou seja, quanto haveria de medo (justificado) e de paranóia (injustificada) em nossas percepções?

É difícil dizer com certeza. Seja como for, viver, hoje em dia, implica assumir (voluntariamente ou não) modos e/ou padrões de exposição a determinados riscos, individualizados ou coletivos, 'escolhidos' ou não e, também, concomitantes estratégias psicológicas para lidar com tal quadro. Estas últimas, a partir de Giddens (1991a), enfocando a realidade do capitalismo avançado e dos riscos globalizados, podem se configurar em quatro modalidades essenciais:

a) "aceitação pragmática": no sentido de 'sobreviver', ou mesmo, de 'resignar-se', concentrando-se no movimento do cotidiano. Nesse caso, parte-se do pressuposto de não se ter controle algum sobre os determinantes da qualidade de nossas vidas, assim, o que resta é dedicar-se à esfera das dimensões básicas de 'admi- 
nistração' do dia-a-dia. O linguajar popular dispõe de expressões ilustrativas a este respeito: "ir levando", "empurrar com a barriga", "deixar como está para ver como é que fica"... Pode haver uma dimensão de entorpecimento capaz de camuflar um profundo descontentamento, ou, então, a esperança de que "dias melhores virão"...;

b) "otimismo sustentado": consiste na crença no primado da razão e do poder da ciência em resolver os problemas humanos (inclusive aqueles criados pela própria tecnociência). Esta é a ótica dos 'expertos', que acreditam que a tecnologia, apesar dos 'efeitos colaterais', existe para melhorar a vida humana (um argumento muito usado: a ampliação, em termos médios, da expectativa de vida). Sob a ótica leiga, implica fé no racionalismo científico como fonte de segurança e sobrevivência (se bem que não custa nada acender uma velinha...);

c) "pessimismo cínico": trata-se de uma estratégia de distanciamento das fontes de ansiedades através de recursos psicológicos que incluem a ironia, o sarcasmo, o deboche. Pode-se ter uma postura irônica sem necessariamente implicar pessimismo (não deixa de ser um 'pragmatismo'). E vice-versa: há os pessimistas 'incorrigiveis', que esperam pela derrocada inevitável. Nesse caso, adotar comportamentos hedonistas (considerados de risco) pode ser uma forma de encaminhamento (o popular "dane-se"...); e

d) "engajamento radical": modo de reação ligado ao ativismo político, mediante movimentos populares/sociais, eventualmente ligados a organizações não-governamentais, que travam lutas para interferir nos impactos de quadros de exposições a riscos (especialmente sob o ponto de vista ambiental). Um exemplo, citado anteriormente, é aquele constituído pela epidemiologia popular.

Não há como negar o vigor presente no risco e em seus discursos. As repercussões são evidentes em inúmeros detalhes de nosso dia-a-dia, a ponto de se incorporar a nossas preocupações de viver constantemente entre exposições e agravos. Diante deste alcance, é preciso ter em mente a dimensão múltipla da 'relatividade' do risco: é um construto produzido em uma época particular, especificada como tardo-modernidade; a categoria está ligada a determinada visão do mundo e do que é a experiência humana, de modo a influenciar os correspondentes enfoques teóricos, conceituais e metodológicos adotados em sua produção, com ênfase em seu caráter probabilístico e respectivas conseqüências; as pessoas lidam e percebem seus riscos (e dos outros) de modos variados - envolvem aspectos que ultrapassam os saberes científicos e mesclam dimensões simultaneamente biológicas, psicológicas, sócio-culturais.

Enfim, se pode haver uma certeza estabelecida acerca das verdades sobre os riscos é que estas são relativas... 
CASTIEL, L. D.: 'Vivendo entre exposições e agravos: a teoria da relatividade do risco'. História, Ciências, Saide - Manguinhos, III (2):237-264, jul.-out. 1996.

Abordam-se aspectos conceituais e teóricos relativos à construção da categoria risco por disciplinas relativas à engenharia de segurança, à epidemiologia e às ciências atuariais. O papel da biologia molecular neste processo é destacado. São consideradas repercussões, tanto em termos psicológicos e sócio-culturais, como sob o ponto de vista da comunicação social. As relações entre as noções de risco, estilo de vida e tardo-modernidade são discutidas. Por fim, a idéia de "relatividade" do risco é apresentada em sua dimensão múltipla: trata-se de um construto produzido em uma época particular; está ligado a determinada visão do mundo e do que é a experiência humana, de modo a influenciar os respectivos enfoques teóricos e metodológicos.

PALAVRAS-CHAVE: risco, epidemiologia, tardo-modernidade, estilo de vida.

\section{REFERÊNCIAS BIBLIOGRÁFICAS}

Alcântara, E. 1995

Almeida Filho, N. 1992

Armstrong, D. 1995

Atlan, H. e

Bousquet, C. 1994

Augé, M. 1994

Ayres, J. R. C. M. 1995

Backett, $\mathrm{K}$.

e Davison, $C$. 1995

Beck, U. 1992

Bonalume Neto, R. 7.1.1996

Bourdieu, P. 1989

Brown, P. 1995

Carter, S. 1995

Castiel, L. D. jul.-set. 1994a
'As pistas no álbum de familia'. Veja, 28 (25), pp. 84-90.

A clinica e a epidemiologia. Salvador, APCE/Abrasco.

'The rise of surveillance medicine'. Sociology of Health and Illness, 17 (3):393-404.

Questions de vie entre le sawoir et l'opinion. Paris, Seuil.

Não-lugares: introdução a uma antropologia da supermodernidade Campinas, Papirus.

Ação comunicativa e conbecimento científico em epidemiologia: origens e significados do conceito de risco. Tese de doutorado, área de concentração em medicina preventiva. São Paulo, Faculdade de Medicina da Universidade de São Paulo.

'Lifecourse and lifestyle: the social and cultural location of health behaviours' Social Science and Medicine, 40 (5): 629-38.

Risk society: towards a new modernity. Londres, Sage.

'A pista errada do dinossauro'. Folha de S. Paulo, Caderno 5, p. 14.

O poder simbólico. Lisboa, Difel.

'Popular epidemiology, toxic waste and social movements'. Em J. Gabe (org.), Medicine, health and risk. Sociological approaches. Londres, Blackwell Publ., pp. 91-112.

'Boundaries of danger and uncertainty: an analysis of the technological culture of risk assessment'. Em J. Gabe (org.), Medicine, bealth and risk. Sociological approaches. Londres, Blackwell Publ., pp. 133-50.

'Uma saúde pública molecular?!'.

Cadernos de Saide Píblica, 10, 3:285-319. 
Castiel, L. D.

1994

Czeresnia, D. e Albuquerque,

M. F. M.

1995

Davison, C.; Smith,

G. D. e Frankel, S. 1991

Davison, C.; MacIntyre, S. e Smith, G. D. 1994

Dean, K.; Colomer,

C. e Perez-Hoyos, S. 1995

Douglas, $M$ 1992

Douglas, $\mathrm{M}$. 1986

Featherstone, $\mathrm{M}$. 1995

Fernicola, N. A. G. G. 1983

Ferreira, A. B. H. 1986

Gabe, J. (org.) 1995

Giddens, A $1991 \mathrm{a}$

Giddens, A. $1991 b$

Gifford, S. M. 1986

Gross, A. G. 1994

Hayes, M. V. 1992

Hayes, M. V. 1991

Janz, N. K. e

Becker, M. H. 1984

Kenen, R. H. 1996
O buraco e o avestruz: a singularidade do adoecer humano.

Campinas, Papirus.

'Modelos de inferência causal: análise crítica da utilização da estatística na epidemiologia'. Revista de Saúde Pública, 29(5): 415-23.

'Lay epidemiology and the prevention paradox: the implications of coronary candidacy for health education'. Sociology of Health and Illness, 13 (1): 1-19.

'The potential social impact of predictive genetic testing for susceptibility to common chronic diseases: a review and proposed agenda'. Sociology of Health and Illness, 16 (3): 340-71.

'Research on lifestyles and health: searching for meaning'.

Social Science and Medicine, 41 (6): 845-55.

Risk and blame: essays in cultural theory. Londres, Routledge.

Risk acceptability according to the social sciences.

Londres, Routledge and Kegan Paul.

Cultura de consumo e pós-modernismo. São Paulo, Studio Nobel.

'Aspecto toxicológico de la contaminación ambiental causada por acidentes'. Bulletin of Sanitary Panamerican Office, 95, 4:352-9.

'Verbete risco'. Novo Dicionário da Lingua Portuguesa. Rio de Janeiro, Nova Fronteira.

'Health, medicine and risk: the need for a sociological approach'.

Em Medicine, bealth and risk: sociological approaches.

Londres, Blackwell Publ., pp. 1-17.

As conseqüências da modernidade. São Paulo, Unesp.

Modernity and self-identity: self and society in the late modern age. Cambridge, Polity Press.

'The meaning of lumps: a case study of the ambiguities of risk'. Em C. R. Janes; R. Stall e S. M. Gifford, Anthropology and epidemiology: interdisciplinary approaches to the study of health and disease. Boston, D. Reidel, pp. 213-46.

'The roles of rhetoric in the public understanding of science'. Public Understanding of Science, 3: 3-23.

'On the epistemology of risk: language, logic and social science'. Social Science and Medicine, 35: 401-7.

'The risk approach: unassailable logic?'. Social Science and Medicine, 33: 55-70.

'The health belief model: a decade later'.

Health Education Quarterly, 11: 1-47.

'The at-risk health status and technology: a diagnostic invitation and the gift of knowing'. Social Science and Medicine, 42: 1.545-53. 
Kleinbaum, D. G.; Kupper, L. L. e Morgenstern, $\mathrm{H}$. 1982

Koopman, J. S. e Longini Jr., I. M. 1994

Last, J. M. (org.) 1989

Latour, B. 1994

Levins, R. 1994

Lima, E. C. 1995

Lupton, D. e Chapman, S. 1995

Lupton, D. 1993

MacIntyre, S. 1995

Miller, D. 1995

Nelkin, D. 1994

Oakes, $\mathrm{M}$. 1990

Parsons, E. e Atkinson, $P$. 1992

Pearce, $N$. 1990

Poole, C. 1988

Richards, M. P. M. 1993

Santos, B. S. 1989

Schulte, P. A. e

Perera, F. P. (orgs.) 1993

Scott, S. e Freeman, R. 1995
Epidemiologic research: principles and quantitative methods.

Belmont, Lifetime Learning Publ.

'The ecological effects of individual exposures and nonlinear disease dynamics in populations'. American Journal of Public Health, 84, 5:836-42.

Verbetes 'probability', 'rate', 'risk'. A Dictionary of Epidemiology.

Nova York, Oxford University Press.

Jamais fomos modernos. Rio de Janeiro, Editora 34.

'Mathematical modeling: concept paper'. Em M. Wilson; R. Levins e A. Spielman, Disease in evolution: global changes and emergence of infectious diseases. Nova York, The Nova York Academy of Sciences, vol. 740, pp. 271-4.

Comunicação pessoal.

'A bealthy lifestyle might be the death of yout: discourses on diet, cholesterol control and heart disease in the press and among the lay people'. Sociology of Health and Illness, 17 (4): 477-94.

'Risk as moral danger: the social and political functions of risk discourse in public health'. International Journal of Health Services, 23 (3): 425-35.

'The public understanding of science or the scientific understanding of the public? A review of the scientific context of the new genetics.

Public Understanding of Science, 4: 223-32.

'Introducing the gay gene. media and scientific representations'.

Public Understanding of Science, 4: 269-84.

'Promotional metaphors and their popular appeal'.

Public Understanding of Science, 3: 25-31.

Statistical inference. Nova York, Epidemiology Resources.

'Lay constructions of genetic risk'.

Sociology of Health and Illness, 14: 437-55.

'White swans, black ravens, and lame ducks: necessary and sufficient causes in epidemiology'. Epidemiology, 1 (1): 47-50.

'Feelings and frequencies: two kinds of probability in public health research'. American Joumal of Public Health, 78, 12:1.531-3

'The new genetics: some issues for social scientists'. Sociology of Health and Illness, 15 (5): pp. 567-86.

Introdução a uma ciência pós-moderna. Rio de Janeiro, Graal.

Molecular epidemiology: principles and practices.

Nova York, Academic Press.

'Prevention as a problem of modernity: the example of HIV and Aids'.

Em J. Gabe (org.), Medicine, bealth and risk: sociological approaches. Londres, Blackwell Publ., pp. 151-70. 
Skolbekken, J.-A. 'The risk epidemic in medical journals'.

1995

Susser, M.

1973

Tannsjö, T. 1993

Taubes, G. 14.7.1995

Uexkull, T. V. 1995

Valenti, J. e Wilkins, L. 1995

Vineis, $\mathrm{P}$. 1995

Watson, J. D.;

Gilman, M.; Witkoski,

J. e Zoller, M. 1992

Williams, S. J e

Calnan, $M$. 1996
Social Science and Medicine, 40: 291-305.

Causal thinking in the health sciences. Nova York, Oxford University Press.

'Should we change the human genome?'. Theoretical Medicine, 14: 231-47.

'Epidemiology faces its limits'. Science, 269.

'Anthropology and the theory of medicine'. Theoretical Medicine, 16: 93-114.

'An ethical risk communication protocol for science and mass communication'. Public Understanding of Science, 4: 177-94.

'Environmental risks: scientific concepts and social perception'. Theoretical Medicine, 16: 153-69.

Recombinant DNA.

$2^{\mathfrak{z}}$ ed., Nova York, Scientific American Books.

'The limits of medicalization?: Modern medicine and the lay populace in late modernity'. Social Science and Medicine, 42: 1.609-20.

Recebido para publicação em julho de 1996. 